\title{
MODEL REQUEST FOR PROPOSALS TO PROVIDE ENERGY AND OTHER ATTRIBUTES FROM AN OFFSHORE WIND POWER PROJECT ${ }^{r}$
}

\author{
Responses Due by
}

Issued by

[Date]

\footnotetext{
${ }^{\Upsilon}$ Prepared by Jeremy Firestone and Dawn Kurtz Crompton, University of Delaware, Center for Carbon-free Power Integration (CCPI) under a grant (DE-EE0000519) from the U.S. Department of Energy. The authors thank Willett Kempton and Paul Gallagher for their comments and suggestions.
} 


\section{Model Request for Proposals to Provide Energy and other Attributes from an Offshore Wind Power Project}

\section{Table of Contents}

Model Request for Proposals to Provide Energy and other Attributes from an Offshore

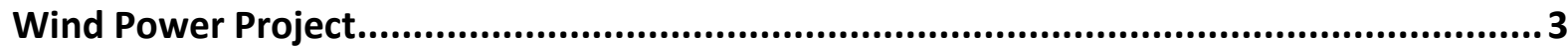

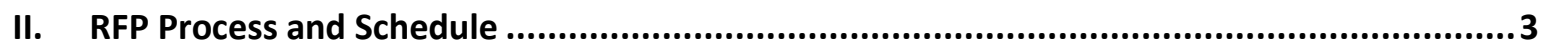

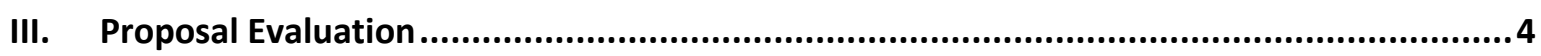

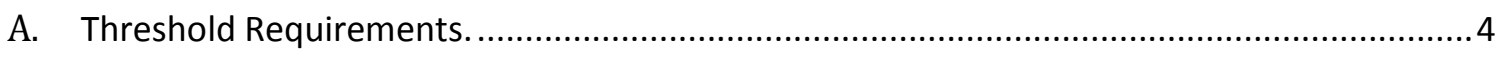

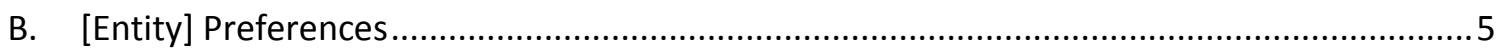

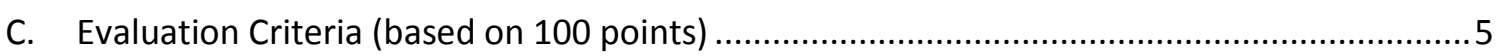

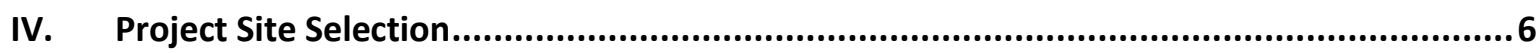

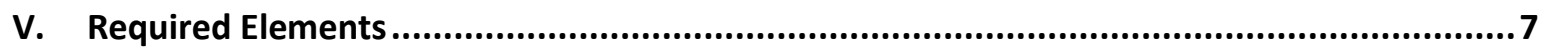

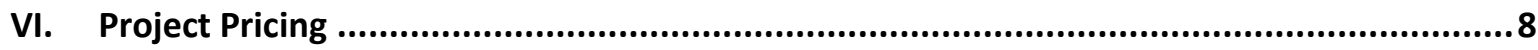

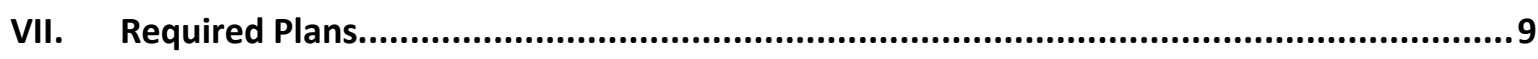

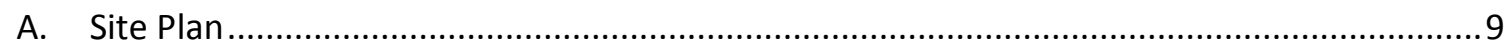

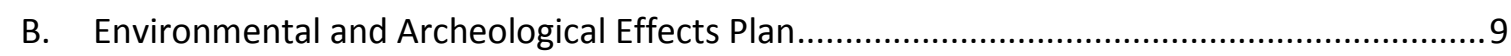

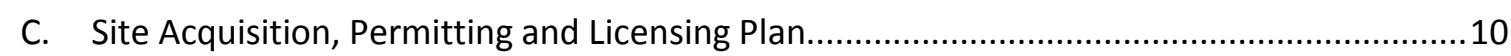

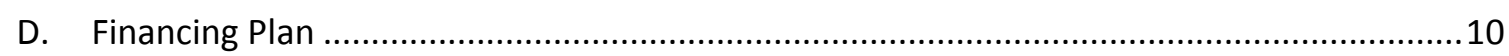

E. Community Outreach, Consultation and Engagement Plan...............................................

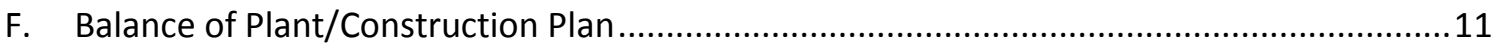

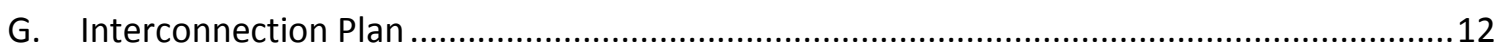

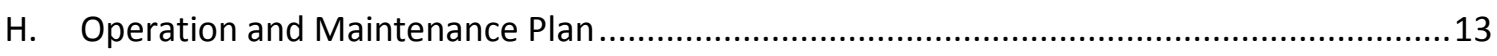

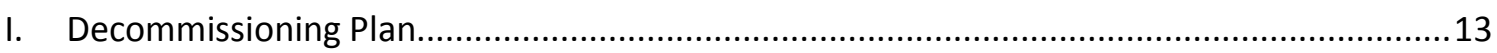

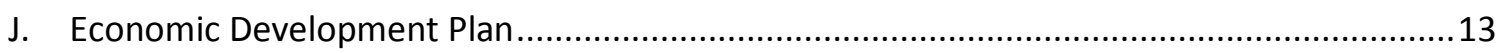

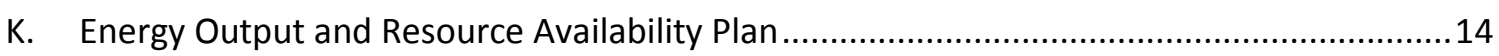

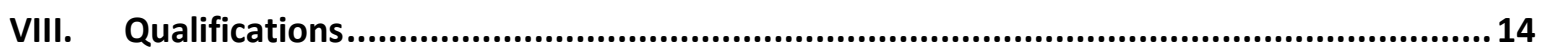




\section{Model Request for Proposals to Provide Energy and other Attributes from an Offshore Wind Power Project}

\section{Introduction and Background}

[Entity] is a [description of entity issuing RFP — state, utility, power authority, etc.]. Through the issuance of this Request for Proposals (RFP), [Entity] is soliciting proposals for the development of up to __ MW of nameplate capacity from one or more offshore wind power projects in the waters off of [State, or other appropriate designation]. [Entity] intends to purchase the energy and other attributes from the Project(s) under a long term Power Purchase Agreement ("PPA") [, subject to approval by the state utility commission].

[Entity] will evaluate proposals from each respondent in accordance with the factors set forth in this RFP. [Entity] nonetheless reserves the right, in its sole discretion, to negotiate with any or all persons responding to this RFP and to accept or reject any or all response to this RFP for any reason. [Entity] also reserves the right, in its sole discretion, to withdraw or modify this RFP in whole or in part at any time. A response to this RFP does not form the basis of, or constitute a binding arrangement and does not commit [Entity] into entering into a PPA, pay any costs incurred in the preparation of a proposal, or procure or contract for product or services of any kind whatsoever. You will be responsible for any and all costs or expenses that you incur in connection with this RFP, including costs of preparing and submitting a proposal and negotiating a PPA and [Entity] will not provide reimbursement for the same. Any material that you submit to [Entity] in response to this RFP will become the sole property of the Authority. Entity reserves the right to utilize any and all ideas submitted in the proposals received unless covered by legal patent or proprietary rights, which must be clearly noted in the proposal submitted in response to this RFP.

Your submission of a proposal in response to the RFP is an acknowledgement and acceptance of its terms.

\section{RFP Process and Schedule}

A. Following is a listing of key events and target dates for this RFP:

\begin{tabular}{|l|l|}
\hline \multicolumn{1}{|c|}{ Event } & Date \\
\hline Issuance of RFP & \\
\hline Notice of Intent to Submit Proposal & \\
\hline Pre-Proposal Meeting & \\
\hline Deadline for Submission of Questions & \\
\hline Response to Questions & \\
\hline Proposal Due Date & Ongoing \\
\hline Proposal Clarifications &
\end{tabular}




\begin{tabular}{|l|l|}
\hline Initial Project Award & \\
\hline Completion of PPA Negotiations & \\
\hline
\end{tabular}

B. Although the filing of a Notice of Intent to Submit Proposal is not a precondition for submitting a proposal in response to this RFP, if you intend to submit a proposal, [Entity] requests that you send a Notice of Intent to Submit Proposal to [Entity] on or before [date]. You may submit such notice:

1. online at RFP website, www.entity.gov/offshorewindrfp;

2. via email to ; or

3. by fax to

The notice should include the Respondent's and a contact person's name, address, phone numbers (office and mobile), and e-mail address.

[NOTE: An option is to make the Notice of Intent to Submit Proposal mandatory. This provides greater certainty, thus enhancing workload planning; however, it may result in a decrease in the number of responsive proposals]

C. A pre-proposal meeting will be held for all interested parties at [location] on [date]. The purpose of the pre-proposal meeting is to provide an opportunity to discuss the RFP with [Entity]. In addition, you may submit questions regarding this RFP to [Entity] until [date] by posting them on the RFP website. [Entity] will post responses to all questions on the website on a rolling basis. These are the sole fora/means by which questions may be posed and answers provided.

D. [Entity] may request clarification of submitted proposals at any time and reserves the right to both request additional information from and to enter into discussions with one or more Respondents; provided that [entity] will not permit any Respondent to alter its proposal after the proposal due date.

E. [Number of] paper copies of your proposal and one copy on a DVD or CD-ROM disk in searchable text format (e.g., MS WORD or searchable PDF) [or uploaded to the RFP website] must be received by at the address below by [time] p.m. [Eastern Standard, Eastern Daylight, Central Standard, etc.,] on [date].

[ADDRESS]

\section{Proposal Evaluation}

A. Threshold Requirements.

You must meet all of the following Threshold Requirements for your proposal to be considered further under this RFP. If your proposal does not meet all of the Threshold Requirements, we will not evaluate it further. The Threshold Requirements are:

1. The nameplate generating capacity must be at least __ MW and may not be greater than _. MW.

2. The PPA must have a term of between [15] and [25] years

3. An authorized officer or agent must certify that the proposal will remain valid 
for [12] months after the date on which proposals are due.

4. The project must be located [insert location] [assuming location preference].

5. The project must be capable of successfully interconnecting with the [RTO/ISO] System.

6. The proposal must be complete and must contain all of the required elements.

7. The proposal must include a detailed plan for mitigating effects of the proposed Project on the environment both during construction and operation.

8. The proposal must contain a detailed schedule of all project milestones including environmental reviews, permit issuance, financing close, startup, commissioning and guaranteed commercial operation date.

B. [Entity] Preferences

A project proposal will be preferred:

1. The extent to which it is likely to produce long term economic benefits and encourage the development of a wind power supply chain for the region.

2. The extent to which is has a high probability of achieving commercial operation by [date].

3. The extent to which you commit to use local labor and materials.

4. The extent to which you accept the draft PPA with no or minimal changes.

5. If you provide price certainty. Price certainty can be accomplished with or without a fixed escalator.

6. The extent to which a project price is not conditioned on future tax credits and other government policies.

7. The extent to which the project location will relieve or reduce congestion in the electric grid system and interconnection system.

C. Evaluation Criteria (based on 100 points)

In order to guide the drafting of your proposal and to assist the [Entity] in evaluating the project, in addition to [Entity] preferences, we will use the following weights to evaluate and to initially rank proposals. The initially highest ranked proposal may or may not be preferred, as tradeoffs must inevitably be made among project economics, project risk and environmental and social considerations. 


\begin{tabular}{|l|c|c|}
\hline \multicolumn{1}{|c|}{ Criterion } & Points & Sub-Category Points \\
\hline $\begin{array}{l}\text { Project Economics } \\
\text { All-in economic value of capacity, energy, RECs and } \\
\text { other attributes }\end{array}$ & 35 & \\
\hline \multicolumn{1}{|c|}{ Project Risk } & 45 & \\
\hline $\begin{array}{l}\text { Respondent's financial condition and creditworthiness, } \\
\text { including demonstrated ability to finance and } \\
\text { decommission the proposed project }\end{array}$ & & 20 \\
\hline $\begin{array}{l}\text { Record and depth of experience in developing, owning } \\
\text { and operating wind projects and/or offshore energy } \\
\text { projects }\end{array}$ & & 15 \\
\hline Technology, Construction and Permitting Risks & & \\
\hline \multicolumn{1}{|c|}{ Environmental and Social Considerations } & 20 & 10 \\
\hline $\begin{array}{l}\text { Potential impact of the project on the environment and } \\
\text { other users of the marine environment. }\end{array}$ & & \\
\hline $\begin{array}{l}\text { Approach to potential affects on communities and } \\
\text { planned outreach, and approach to maximizing } \\
\text { economic and community benefits } \\
\text { of the project. }\end{array}$ & & \\
\hline
\end{tabular}

[NOTE: This model is intended to be a single source offshore wind RFP. In the event that a State seeks multi-source bids (e.g., land-based wind, solar, coal, natural gas, nuclear, hydropower, etc.), we recommend several modifications to the weighting scheme. First, the "Project Economics" category should include a second criterion for price stability, as many ratepayers and utility commissions may value stable prices as much or more than initial price. Second, the "Environmental and Social Considerations" category should include health impacts. Third, the Entity should either add per-MWh technology-specific, life-cycle climate $\left(\mathrm{CO}_{2}\right)$, environmental and health impact costs to bid prices under the "Project Economics" category or it should increase the "Environmental and Social Considerations" category to $50 \%$ ]

\section{Project Site Selection}

[NOTE: This section is applicable only if Entity has preferred site locations]

[Entity] has conducted preliminary wind resource assessments, site screening studies, environmental studies and other technical studies (hereinafter jointly "area studies") with respect to the waters of [X region and $\mathrm{Y}$ region] to investigate potentially feasible locations for siting projects, and to identify Preferred Project Siting Areas (PPSAs).

If areas have been pre-selected, they will be available on [Entity] website. [Entity] makes no guarantee as to the accuracy or completeness of supplied area studies, nor to any data or information made available to you. You are encouraged to independently verify any sources, methodologies, and studies. Applicant has a continuing obligation to file an addendum if there is any negative information.

While the PPSAs represent the [Entity's] preliminary assessment of potentially feasible locations for Projects, you may propose Projects located elsewhere. 


\section{Required Elements}

If your response does not include all of the information set forth in this section it may be deemed non-responsive and subject to rejection:

A. A cover letter under which you agree to be bound by the terms of the RFP, signed by authorized representative.

B. A summary term sheet that includes key terms and conditions, prices and milestones.

C. A project schedule from the date of proposal selection to commercial operation. Entity will set forth a target date for selection and will use best efforts to ensure that a proposal is selected by that date.

D. Name, title, address, landline, cell number, e-mail address and fax number of the primary contact regarding your proposal.

E. Your legal status (corporation, partnership, LLC, etc.), date formed, principle place of business, state of incorporation, etc., and identification of any parent, subsidiary or affiliates.

F. A disclosure of any instances in which you, any of your officers, directors or partners, or any affiliates was:

1. convicted of any felony;

2. convicted of any crime, subject to a civil proceeding or deemed to be in non-compliance with any obligation related to the generation, sale, transmission, purchase or use of power, energy, or Renewable Energy Credits (RECs); or

3. convicted of any crime or subject to a civil proceeding related to conversion, theft, mischief, fraud, misrepresentation, false statements, unfair or deceptive business practices, anti-competitive acts or omissions or collusive bidding or other procurement or sale-related irregularities

G. An account of your business history, including your record and depth of experience in developing, owning and operating wind projects and/or offshore energy projects.

H. Description of your supplier and subcontractor plans, including how your project will produce long term economic benefits and encourage the development of a wind power supply chain for the region.

I. The proposed term, which may not exceed __ years, of the PPA.

J. The total rated capacity (MW) of the Project.

K. The estimated and guaranteed Commercial Operation Date(s) for the Project. If the project will be constructed over more than one season, you are to specify the 
installed capacity (MW) by date.

L. If you claim that any material in your submitted proposal is entitled to be treated as confidential or proprietary, you must mark that specific material, and only that material, as "Confidential and Proprietary." [Entity] will treat the material as such to the extent consistent with the [Entity's] obligation under applicable laws, regulations and legal processes, except that, it is acknowledged and agreed that [Entity] may disclose such material as necessary for the evaluation of your proposal. You also acknowledge and agree that, to the extent a claim is made by a third party for disclosure of the material, you will promptly provide a detailed justification for any material claimed as confidential or proprietary.

[NOTE: In anticipation of state freedom of information act requests, States may consider requiring Applicants to submit a redacted copy of their proposals. The redacted copy, which should be submitted within thirty (30) days of bid submittal, should disclose the name of the applicant and the size and location of the proposed development. Because pricing arguably may contain proprietary information, and a State may wish to facilitate further sharpening of qualifying bids, it also may consider allowing that price be redacted after weighing the effects of such a redaction against the interests of transparency.]

M. Project Pricing as specified in Section V.

N. All Required Plans specified and detailed in Section VII.

O. Your Qualifications in response to Section VIII.

\section{Project Pricing}

You must answer subsections A and B below. If your price as set forth in subsections A and B is any way contingent on either investment or production tax credits or receipt of a loan guarantee, you must answer subsections C, D and/or E, as appropriate. If in addition to subsection A, you would like to propose that [Entity] assume cost of interconnection and/or decommissioning, you must answer subsections $\mathrm{F}$ and $\mathrm{G}$, as appropriate. In addition, you also may propose alternative approaches including turnkey project or joint venture, but in any event, you must include a bid price (A and B) that addresses the default approach-a PPA.

A. Total Initial Price- Elements (Energy, Capacity, RECs and other environmental attributes)

B. Escalator, if any.

C. Price without investment or production tax credits.

D. Price without loan guarantee.

E. Price without investment or production credits and without loan guarantee.

F. Price if [Entity] assumes cost of interconnection.

G. Price if [Entity] assumes cost of decommissioning. 


\section{Required Plans}

A. Site Plan

1. Provide a detailed map of the Project Site Area and a full and complete description of the activities that you will undertake to locate and secure the specific area in which the Project will be located reflecting considerations for:

a. Water depth.

b. Geotechnical evaluation plan.

c. Project distance from shore.

d. Interconnection arrangements.

e. Arrangements for leasing submerged lands for Project.

f. Right of way agreements for on-shore transmission, if required.

g. Site layout drawing (with latitudes and longitudes) showing locations of significant project facilities including turbine array, MET towers, offshore substation, submarine and onshore transmission lines, landfall sites, right of ways and point of delivery, including any substation upgrades.

h. Relation of Project to current or contemplated uses such as sand borrow areas, commercial shipping lanes, commercial and recreational fishing areas, fish, marine mammal and wildlife habitat, military, oil and gas extraction, archaeological and historical sites, etc.

i. Onshore Wetlands, parklands, beaches, boardwalks or other public access uses, and other significant land features.

2. Describe the staging areas/ports that you anticipate utilizing.

3. Define the attributes that make the site desirable, and list any constraints, potential problems or limitations with siting an energy facility and the accompanying transmission in the area.

4. If you have an agreement with the wind turbine vendor to supply wind turbines at the site, provide the physical dimensions, weights and design loads of the turbine to the extent available. Provide details of the turbine models that may be utilized including a commercial description of the turbine. In any event, provide a procurement plan, decision matrix for deciding on turbine make, model, and estimated rated capacity.

5. Specify the total nameplate capacity (in MW) that Applicant is proposing to install.

B. Environmental and Archeological Effects Plan

Provide detailed feedback on the following topics with respect to your plan for addressing the environmental effects of the Project:

1. Proposed studies to be undertaken to assess the potential environmental impacts of the Project, Project footprint plan drawing showing the affected areas for construction and operation and any alternatives that are being considered. 
2. Preliminary estimation of significant environmental impacts and mitigation measures expected to be undertaken and total estimated costs of those mitigation measures. Note that a reduction in planned expenditures for mitigation may be grounds for corresponding reduction in PPA price.

3. Pre-construction submerged lands analysis.

4. Provide preliminary analyses of:
a. aquatic life impacts;
b. benthic impacts;
c. avian/bat impacts; and
d. commercial and recreational fishing impacts of the Project;
e. visual/aesthetic impacts and the role of viewshed analysis and photo-simulations associated with the Project.
f. onshore impacts of (short term) construction and (longer term) transmission infrastructure.

[NOTE: This model is intended to be a single source offshore wind RFP. In the event that a State seeks multi-source bids, States should require information on environmental and health effects, including but not limited to: estimated displacement of $\mathrm{CO}_{2}$ from a proposed project (yearly or over project lifetime, using same timeframe as environmental impacts); human health benefits (avoided mortality and morbidity); reduction of cooling water from existing power plants and associated reduction in biological morbidity; and net impact of the project on the environment, including environmental impacts of construction and operation, and displacement of other polluting power production.]

\section{Site Acquisition, Permitting and Licensing Plan}

Provide following details of Applicant's proposed Permitting and Licensing Plan:

1. A listing of all environmental, regulatory and other federal, state and local permits, authorizations, and certifications (hereinafter, jointly "approvals") required for construction and operation of the Project.

2. A proposed schedule for securing each approval, including identifying key individuals and firms responsible for such approvals, and any relevant experience they may have.

3. Identify any anticipated permitting issues, and related solutions.

4. Documentation of any consultation that has occurred with the appropriate governmental agencies who are responsible for approvals or that are otherwise required to be consulted during an approval process.

D. Financing Plan

Provide the following information concerning your plan for securing both short-term and long-term financing for the Project:

1. A detailed description of proposed short-and long-term financing arrangements. A list of all equity partners, sources of equity and debt, debt structure. 
2. Demonstrate that financial arrangements are sufficient to support the Project through construction and the PPA term.

3. Describe plans for financing the decommissioning of the Project at the end of its useful life. Include the estimated decommissioning costs in current dollars, and how the estimate was determined.

4. Show proposed capital structure for the Project.

5. A schedule showing all major projects that you have developed or financed in the past ten (10) years.

6. Provide details of any events of default or other credit issues associated with any projects listed in response to the immediately proceeding inquiry.

7. Identify proposed guarantor(s) for the Project and provide documentation of the guarantor's creditworthiness (including the three (3) most recent audited financial statements of the guarantor).

8. Information and evidence concerning your financial condition and creditworthiness, including your three (3) most recent audited financial statements.

E. Community Outreach, Consultation and Engagement Plan

1. Describe any community outreach activities that you have conducted prior to submitting your proposal in response to this RFP.

2. Provide a full description of your plan to reach out to, consult with, and engage local communities and Indian Tribes, as applicable.

3. If you are notified that your bid has been successful, you will be required to address the following, and may therefore include the following details now:

a. A description of post-selection activities and how such activities would be coordinated with [Entity].

b. The plan for educating affected communities about the Project.

c. The plan to secure community input about Project on an ongoing basis.

d. The plan to integrate community needs and concerns into Project planning to the extent practicable.

e. Any plans to use local labor and materials.

F. Balance of Plant/Construction Plan

1. Balance of Plant: Provide the following information, specifically the electrical collection system, offshore substations, onshore substations, staging and construction areas and the operation and maintenance facilities:

a. Description of other project components (cabling, meteorological tower(s), communications systems, SCADA).

b. Project design, including tentative layout of turbines, offshore substation, cabling, etc.

c. Supply chain description (manufacturing locations, transportation). 
2. Construction Plan: Provide the following information with respect to planned Project construction arrangements:

a. Provide general overview of all aspects of the Construction Plan from commencement of construction to testing and commissioning of the Project.

b. Provide detailed schedules for construction and commissioning the Project.

c. Describe the contracting strategy to be employed (i.e., EPC, other) and provide an organizational chart.

d. Describe staging areas for assembly of turbine components and foundations and show plan for meeting storage and lay-down requirements.

e. Provide information on anticipated port(s) for construction and describe availability of road and rail service to the Port.

f. Describe how you will engineer, design, construct and commission the Offshore Substation(s).

g. Specify the details of construction/installation vessel and crew requirements.

h. Describe vessel availability and strategy to acquire appropriate construction/installation vessels, vessel design, vessel availability, vessel access (seasonal issues) and address Jones Act compliance

i. Describe any ice loading abatement strategies to be employed to secure both the towers and foundations (for Great Lakes states only).

j. Describe any inherent risks or limitations that may arise during construction that are specific to this project and location and specify more generally construction mitigation strategies.

k. Describe any plans for upgrading port facilities, as necessary.

\section{G. Interconnection Plan}

1. Specify a Point of Delivery (POD) for energy.

2. Provide the following information with respect to the interconnection for each Project Offshore Substation with the existing or planned transmission infrastructure.

a. Describe the Project transmission route(s), including landfall sites.

b. Describe how the Project will be interconnected with the transmission system (e.g., connect to an existing substation, install a new substation at an existing line, tie-in to an offshore transmission trunkline, etc.), the rationale for the interconnection cable route, and how you will manage the interconnection process.

c. Create an electrical one-line diagram for the underwater cable and appurtenances to be located between the Offshore Substation and the POD.

d. Provide Offshore Substation and Onshore Substation technical parameters and requirements, design specifications, and operating standards.

e. Detail the proposed location of converter station (if HVDC).

f. Describe arrangements for securing necessary rights-of-way.

3. Specify schedule for completing interconnection studies and the negotiation of the Interconnection Agreement. You must install all interconnection 
facilities including offshore cables, substations and appurtenances as well as all onshore facilities up to, and including, the interconnection at the POD.

You must also ensure that the energy produced by the Project is deliverable to the POD. You will be responsible for the cost of any substation upgrades required for the interconnection of the Project at the POD. If the POD is not at an existing substation on the transmission system, you will be responsible for constructing a new substation as part of the interconnection.

H. Operation and Maintenance Plan

1. Specify location(s) (e.g., specific ports) and provide descriptions of O\&M facilities.

2. Describe plans for maintenance vessel design and availability (including seasonal considerations).

3. Identify party or parties who will be responsible for scheduled maintenance activities, and include their qualifications for such tasks.

4. Show scheduled maintenance plans including minimum/maximum planned outages.

5. Specify anticipated response times for unscheduled maintenance events and limiting factors, with consideration of weather-related conditions.

6. Detail plans for staffing, spare parts supply, remote dispatch and control and emergency power supply.

7. Show an array interconnection cable repair plan.

8. Document a health and safety plan, including emergency rescue plan.

I. Decommissioning Plan

1. Provide a complete description of your plan to decommission the project and fund such decommissioning, including dismantling and removing:

a. wind turbines and towers;

b. all underground and overhead collection and transmission lines;

c. MET towers;

d. transformer stations;

e. living quarters; and

f. any other related structures.

2. Describe how you propose to restore project areas to their original state, including, but not limited to:

a. how structures will be removed; and

b. what steps will be taken to restore lands and vegetation and otherwise return the environment to its natural state

J. Economic Development Plan

Provide a complete description of your plans to optimize the economic development opportunities associated with the project, including the: 
1. estimated percentage of locally, regionally and nationally sourced Project material;

2. estimated percentages of local labor that will be involved in the construction of the Project and the ongoing operation and maintenance of the Project, to include estimates on:

a. total number of permanent jobs;

b. average salaries and benefits anticipated; and

c. state taxes generated, including state and municipal taxes.

3. The development of wind generating facilities and component manufacturing in the state, region and nation.

4. The construction and maintenance of wind project installation and maintenance vessels in the state and region.

K. Energy Output and Resource Availability Plan

Capacity and Energy Output -Provide the following information:

1. Projected energy generation and capacity factors (as measured at the POD) from the Project. Provide the gross to net calculations and losses considered.

2. Show the basis for the projections along with the calculation methodology for computing projected annual energy amounts.

3. Provide a statement as to the certainty and probability of wind evaluation and energy projections.

a. State the source or third party that provided the calculations and assessment. Provide sources of information, where data was measured, and assumptions for wake and line losses.

4. Estimated monthly and hourly energy outputs from the Project (as measured at the POD) for a typical calendar year, the diurnal pattern of wind/energy generation, as well as a single year time-power series graph or table.

5. The turbine manufacturer's guaranteed availability if applicable. This information must be included if Applicant has a pre-existing contract with a manufacturer for turbine supply.

6. If the Project has the capability to supply Ancillary Services (as defined by the [RTO/ISO], specify the particular Ancillary Services that the Project has the capability to supply and describe how such Ancillary Services would be provided.

\section{Qualifications}

Demonstrate your capability to develop, design, finance, construct, operate and maintain an offshore wind project by providing the following information:

A. Documentation of your wind project development, design, finance, construction 
and operating experience.

B. Documentation of offshore energy development design, finance, construction and operating experience.

C. Verify your financial soundness.

D. A proposed organizational chart showing the Project team along with the resume and Letter of Commitment pertaining to each team member. Include a detailed description of your Project team's qualifications, including those responsible for permitting, designing, engineering, procuring, constructing, operating, overseeing and maintaining the Project.

E. You must include references. If you have developed three or fewer projects, a reference from each of the projects must be submitted. If you have developed more than three projects, you must include up to three references from prior development projects, preferably from projects in which you employed financing arrangements similar to the arrangements contemplated herein. Preferred references include offshore wind projects, land-based wind projects, and offshore oil and gas projects (in that order).

F. Disclose whether you or any of your team members have had a contract terminated for non-performance or poor performance or been a party to litigation alleging nonperformance, poor performance, and/or errors. 